\title{
PUBLICIDADE DAS MARCAS: A APLICAÇÃO DA SEMIÓTICA DISCURSIVA NA COMUNICAÇÃO PUBLICITÁRIA PARA A DIVULGAÇÃO DO DISCURSO DA MARCA.
}

\section{BRAND'S ADVERTISING: THE USE OF THE DISCURSIVE'S SEMIOTICS IN THE ADVERTISIN'S COMMUNICATIONS TO DISSEMINATION OF THE BRAND'S DISCOURSE.}

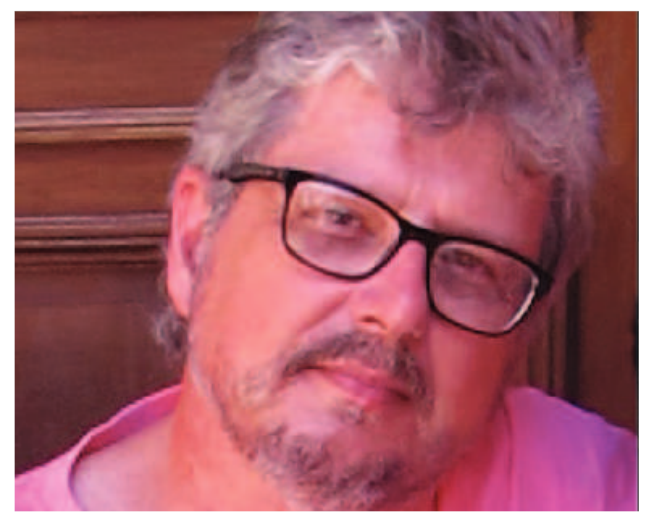

\author{
Alvaro Roberto Dias \\ Doutor em Mídias do Conhecimento do Programa de Pós- \\ Graduação em Engenharia e Gestão do Conhecimento \\ EGC/UFSC \\ Professor de curso de especialização da Universidade do \\ Vale do Itajaí - UNIVALI \\ alvarodias@univali.br,prof.alvarodias@gmail.com
}

\section{RESUMO}

$\mathrm{O}$ artigo apresenta como a publicidade pode construir a identidade de uma marca comercial. Assim, pretende discutir a relação das identidades da marca com a publicidade, como sua imagem é construída através dos discursos, impactando diretamente nos projetos da marca através das percepções do público alvo e de seus diferentes comportamentos como atitudes, modos de agir e reagir. Para exemplificar, analisou-se o comercial L'Odyssée de Cartier (A Odisséia de Cartier), produzido em 2012 para comemorar os 165 anos dessa joalheria. O aporte teórico foram o pensamento de Andrea Semprini sobre semiótica discursiva da marca e o de Mark Batey sobre modelo de significado da marca.

\section{PALAVRAS-CHAVE \\ Branding. Discurso. Publicidade.}

\section{ABSTRACT}

The article presents how advertising can build the identity of a brand. Therefore, it aims to discuss the relationship of the brand identities with advertising and how its image is built through discourses, impacting directly on the brand projects through the target's audience perceptions and their different behaviors, such as attitudes, ways of acting and reacting. Thus, the commercial L'Odyssée de Cartier (The Odyssey of Cartier), produced in 2012 to commemorate the 165 years of the jewelry, was analyzed. The theoretical support for this studye were the thinking of Andrea Semprini on brand's discursive semiotics and of the thinking of Mark Batey on the model of the brand's meaning.

\section{KEYWORDS}

Branding. Discourse. Advertising. 


\section{INTRODUÇÃO}

A identidade de uma marca é o resultado do processo de simbolização, da construção da autoimagem de uma entidade ou de uma individualidade. $O$ seu caráter simbólico surge do fato das simbolizações interagirem na composição dos valores expressos pelas marcas, impondo a necessidade da análise sobre como ela se comunica com o mercado e qual é a importância e a função de sua aparência na comunicação, construindo sua identidade. Deve-se considerar que não basta elaborar uma história (storytelling) interessante e tentar associá-la à marca isso pode ser necessário, mas não é suficiente; uma vez que a imagem de uma marca é também determinada na mente do consumidor pelo contato com as diversas formas de expressão desta marca, incluindo o uso de serviços e produtos.

Assim, um discurso eficiente deve sintetizar, relembrar, atualizar e reforçar uma relação que já foi previamente construída entre os consumidores e a marca, contribuindo para o que se chama de discurso da marca. Os estudos revelam que diferentes tipos de discursos, como o publicitário, por exemplo, evidenciam essa função de "representar" e/ou "construir" os significados do mundo. Dentre demais estudiosos, Floch (1993) se interessa pelos processos discursivos da marca, considerando para as análises de identidade apenas manifestações concretas emitidas pela marca, composta por elementos invariantes e elementos variantes: uma dimensão sensorial, que se refere à expressão e uma dimensão inteligível que se refere ao conteúdo. Tomando como base a distinção do autor, poder-se-ia relacionar a dimensão sensorial às atividades de design, já que essa toma como base o plano da expressão e a dimensão inteligível às atividades da publicidade, visto que lida com as informações no plano do conteúdo, e assim construir o discurso da marca.

Para Floch ambas as dimensões possuem componentes variáveis e invariáveis e a identidade da marca é baseada na dialética entre os componentes invariáveis das dimensões. O componente invariável do plano inteligível é nomeado de ética da marca, enquanto o componente invariável do plano sensorial é nomeado estética da marca.

Figura 1: A integração da marca

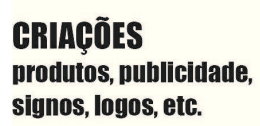

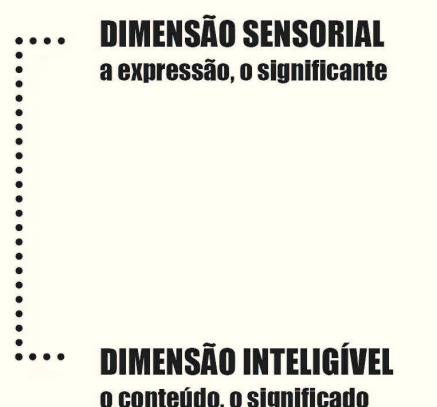

o conterúdo, o significado

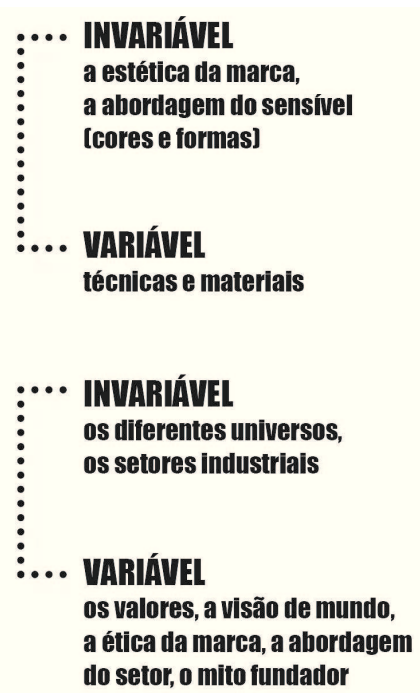

Fonte: SEMPRINI (2010)

A publicidade, para a semiótica francesa, apoia-se no percurso da manipulação e se efetiva quando o sujeito se deixa manipular, transformando-se no destinatário, e, assim, estabelecendo um contrato entre destinador (marca) e destinatário, a partir do qual toda a narrativa desenvolver-se-á. 
Greimas e Courtés (2008) destacam as quatro formas principais de manipulação: tentação, intimidação, provocação e sedução. E Floch (1993), resumidamente, divide essas quatro formas em duas categorias:

1. Ofertas de valores:

- Tentação (Valores eufóricos)

- Intimidação (Valores disfóricos)

2. Construções Identitárias:

- Sedução (Imagem positiva)

- $\quad$ Provocação (Imagem negativa)

Para levar o destinatário (público-alvo) a agir segundo sua vontade, o destinador (marca) se utiliza, através da publicidade, dessas estratégias de manipulação. Na tentação, o produtor do discurso tenta convencer o destinatário a fazer algo por meio de uma espécie de suborno, pela oferta de valores que este destinatário deseja. Assim, para que a manipulação seja eficaz, é preciso que a oferta seja interessante, desejável. $O$ sujeito é levado a fazer o que o outro deseja ou a crer no manipulador para que venha a adquirir o que deseja. A tentação, portanto, é ineficaz quando os valores ofertados não são desejáveis ao destinatário. A segunda forma de manipulação é a chamada "intimidação". Ao contrário da primeira, em vez de oferecer valores interessantes, na intimidação o manipulador ameaça retirar do seu destinatário algum(s) valor(es) que ele possui ou acrescentá-lo de valores que ele não deseja.

A terceira forma de manipulaçãoéa "sedução". Agora já não se trata de promessas e ameaças, mas de exaltações sinceras, ou não, que o manipulador faz em relação às características do destinatário. $O$ sedutor é aquele que tenta convencer o outro elogiando-no, notando-no ou até destacando com exagero as suas virtudes; esse ato aparentemente benévolo leva indiretamente o destinatário a agir de forma a confirmar os elogios feitos. Por último, também se pode manipular alguém por meio da "provocação". Neste caso, em vez de exaltar as características do outro, o manipulador deprecia-nas e, da mesma forma, o destinatário se sente forçado a agir, desta vez para alterar a ideia negativa que o outro dele faz. Então, percebese que é possível estabelecer - nas imagens manipuladas através dos discursos e nas percepções do público-alvo e seus diferentes comportamentos (com atitudes, modos de agir e reagir) - a relação das identidades da marca com a publicidade, ganhando uma dimensão e impactando diretamente nos projetos da marca.

\section{IDENTIDADE DAS MARCAS}

Uma das grandes estratégias das marcas comerciais hoje é a busca de um diferencial para atingir e manter os seus consumidores, buscando criar um reconhecimento e uma identificação. A marca quer ser percebida. Uma marca só passa a ser marca quando as pessoas a associam a outras coisas. A marca, assim, passa a ter uma história e interferir na maneira de como as pessoas veem os produtos, ficando definitivamente ligados à marca.

Os adeptos das marcas carregam seu logotipo (a expressão nominal visual da marca) em todos os lugares, nas roupas e em objetos de uso pessoal. Vão a lugares onde o logotipo os espera, loja, restaurantes, bares, shows e eventos. Como acontece entre as pessoas, há um processo de atração e paixão entre consumidores e marcas: há um primeiro impulso de atração, há um segundo impulso de experimentação e há, enfim, a experiência do convívio e do uso. Estes conceitos, manipulados para serem de valorização, são frutos das construções do imaginário dos sujeitos daquele universo; isto é, são conceitos subjetivos, simbólicos, que muitas vezes só fazem sentido naquele universo próprio.

Villas-Boas faz a articulação entre o design e a identidade cultural, pois acredita que os estudos culturais, e sua articulação, devem ser ferramentas de estudo do design. Ele acredita que o design é um discurso e como tal espelha a condição cultural na qual e para a qual foi concebido, ao mesmo tempo em que contribui 
para produzir, realimentar ou transformar esta mesma condição cultural. "Os estudos culturais tendem a questionar as práticas metodológicas tradicionais ou as misturam de acordo com as necessidades apresentadas pelo objeto de análise no curso da pesquisa" (VILLAS-BOAS, 2002, p. 10).

Qualquer pessoa não tem como olhar para qualquer coisa sem atribuir a ela um sentido - e sem que ela não se configure nas nossas relações construídas socialmente - dessa forma, qualquer informação, principalmente a visual, é uma expressão cultural, ou seja, "não é um objeto em si mesmo, porque aos termos contato com ela obrigatoriamente a estamos incluindo na nossa história individual e socialmente falando - e, portanto, estamos incluindo em nosso jogo individual e social, e a este jogo damos o nome de cultura". (VILLAS-BOAS, 2002, p. 16).

A grande síntese dessa imensa rede de ícones são os símbolos da marca, os logotipos, seus mínimos denominadores comuns, a tradução direta e imediata de um longo e complexo texto corporativo, que contém desde os benefícios e atributos físicos do produto até uma filosofia de vida e de comportamento que a marca busca transmitir. É por onde o consumidor se relaciona e se identifica (no duplo sentido da palavra).

A marca é fruto de um planejamento de mercado e de comunicação que organiza as ações estratégicas para construir e projetar essa marca no mercado. $O$ seu conhecimento levara à preferência do consumidor na compra, ser reconhecida no mercado por seus atributos - que podem ser tanto técnicos como simbólicos - em detrimento de outros produtos de marcas desconhecidas. A qualidade percebida constrói a imagem da marca e o seu nome, os quais estão associados à qualidade perceptível do público-alvo, influenciando na decisão de compra e na sua lealdade. O valor da marca estabelece associações que irão vinculá-lo a outras coisas, como por exemplo, a um estilo de vida ou à uma personalidade, provocando diversas experiências para aqueles que a possuem. As associações podem tanto envolver as características tangíveis, como a tecnologia superior, por exemplo, como as intangíveis, que podem significar status, poder e prestígio, entre outros.

Ainda que com suas características específicas, em termos de linguagem, envolvimento de sentidos diferentes no processo de percepção, cognição e interação, podem ser considerados ferramentas altamente eficazes de comunicação.

\section{A MARCA COMERCIAL E SUA IDENTIDADE CONSTRUIIDA PELO DISCURSO}

O caráter simbólico das marcas surge do fato das simbolizações interagirem na composição dos valores expressos por elas, impondo a necessidade da análise sobre o que é a marca, como ela se relaciona com o mercado e qual é a importância e a função de sua aparência na comunicação, construindo sua identidade. Devese considerar que não basta elaborar um slogan interessante e tentar associá-lo à marca, isso pode ser necessário, mas não é suficiente; uma vez que a imagem de marca é pré-determinada na mente do consumidor pelo contato com as diversas formas de expressão da marca, incluindo o uso de serviços e produtos. 
Figura 2: A propaganda como comunicação da marca

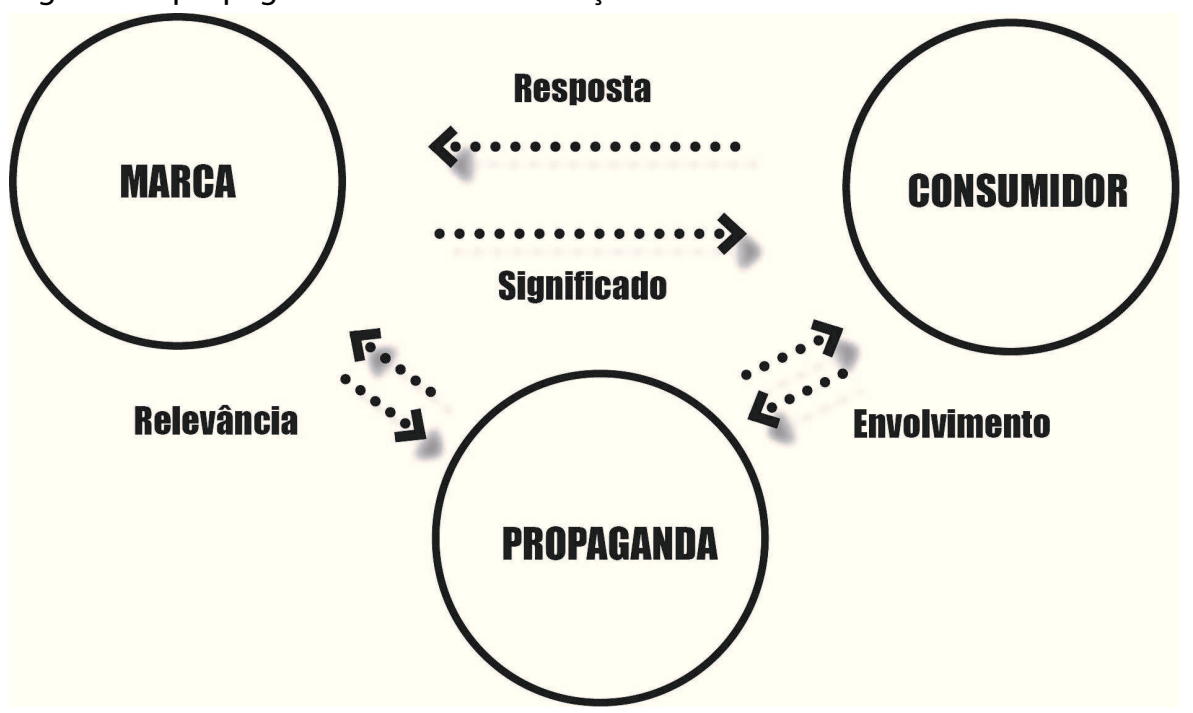

Fonte: BATEY (2010)

A imagem da marca se compõe de sua identidade (no sentido material e simbólico) e de seus valores (atribuídos por ela mesma e por seus consumidores) que impactam seus públicos através de significados e de emoções. As marcas tem seu significado acessado por informações sensoriais e por padrões arquetípicos.

Figura 3: Modelo de significado de marca

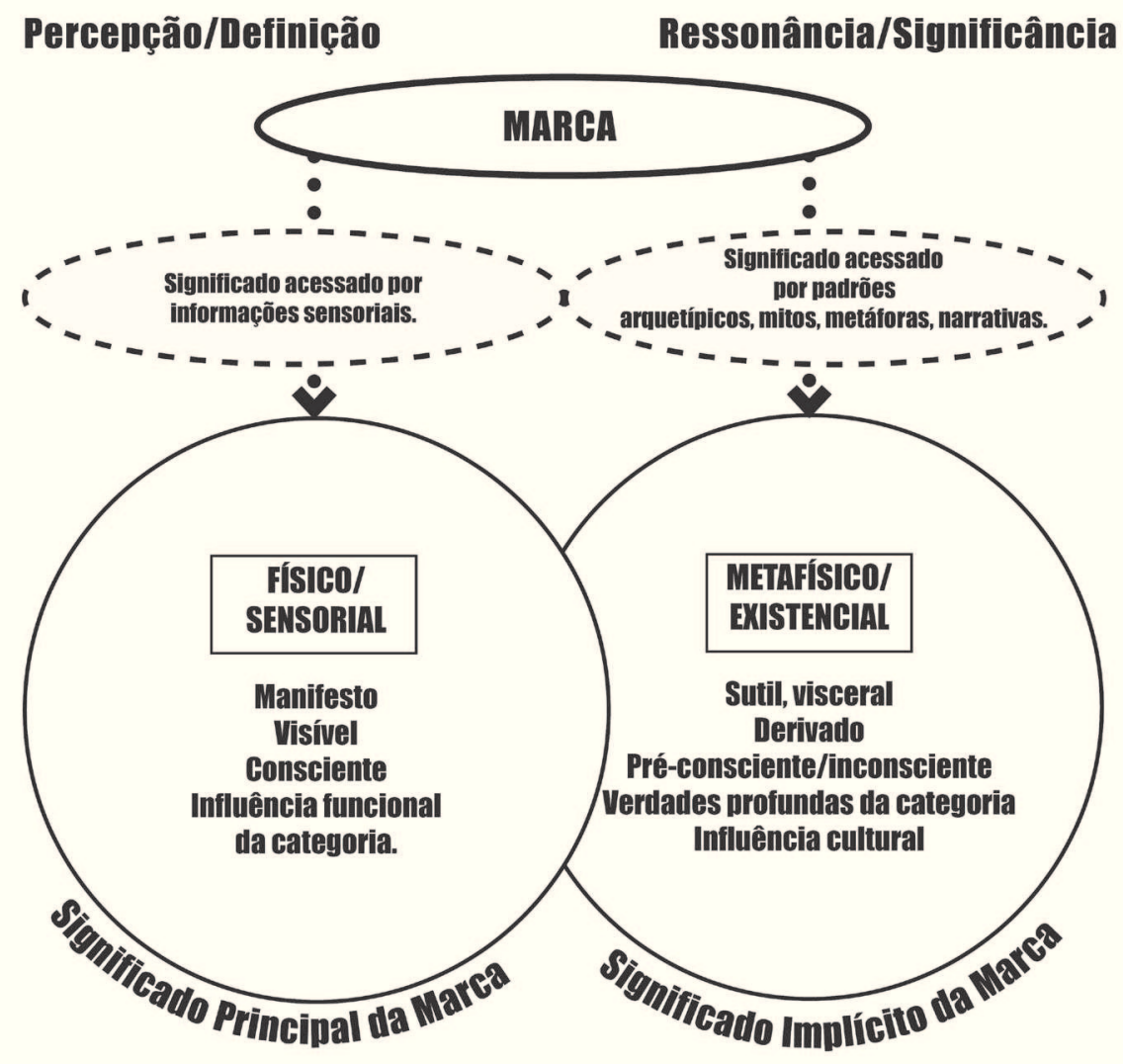

Fonte: BATEY (2010) 
A identidade da marca é resultado de todo o processo de interação entre a marca e os seus públicos, do que resulta uma dada percepção, na base da qual estará a maior ou menor predisposição para atribuir à marca um valor elevado no mercado. Logo, analisar a marca é estudar a relação empresa-públicos, cuja gestão eficiente parece trazer inúmeras vantagens pela capitalização no valor da marca. E, nesse sentido, o conceito de identidade parece ser simultaneamente um produto (efeito final) e um processo (ao longo do tempo).

O projeto de uma marca, segundo Semprini (2010), compõe-se da enunciação fundamental (sua razão de ser), da promessa (a projeção da enunciação fundamental), da especificação da promessa (a elaboração de um caráter original à promessa), da inscrição de um território (quando o procedimento enunciativo começa a se concretizar) e de valores (as características e as nuances que permitem a marca definir sua abordagem).Todavia, a marca ganha dimensão quando ela se manifesta num processo de construção da identidade da marca. Manifestações essas que impactam diretamente na imagem e nos projetos da marca através das percepções do público alvo e novamente interferindo no projeto inicial.

Figura 4: A identidade de marca



Fonte: SEMPRINI (2010)

O processo de construção da marca e suas manifestações são resultantes de programas e ações de comunicação que, ao atuarem como manifestações da organização, interferem e constroem, ao mesmo tempo, a identidade e a imagem - fruto da interação entre a organização, seu ambiente e o(s) público(s) a quem ela se dirige; sendo a publicidade uma das ações de comunicação mais tradicionais. Assim, a comunicação da marca se expressa através da comunicação formal; ou seja, através da publicidade, uma atividade profissional dedicada à difusão pública de ideias associadas a empresas, produtos ou serviços e, especificamente nesse caso, à propaganda comercial das marcas. A publicidade faz a mediação entre a marca e o consumidor num processo de respostas com significados embutidos. Isso significa que a marca adquire relevância através da publicidadee o consumidor é envolvido por ela. Tudo isso, segundo Semprini (2010), através de um discurso (aqui no caso, publicitário) construindo uma narrativa simbólica. 
Figura 5: O processo do significado em seu contexto

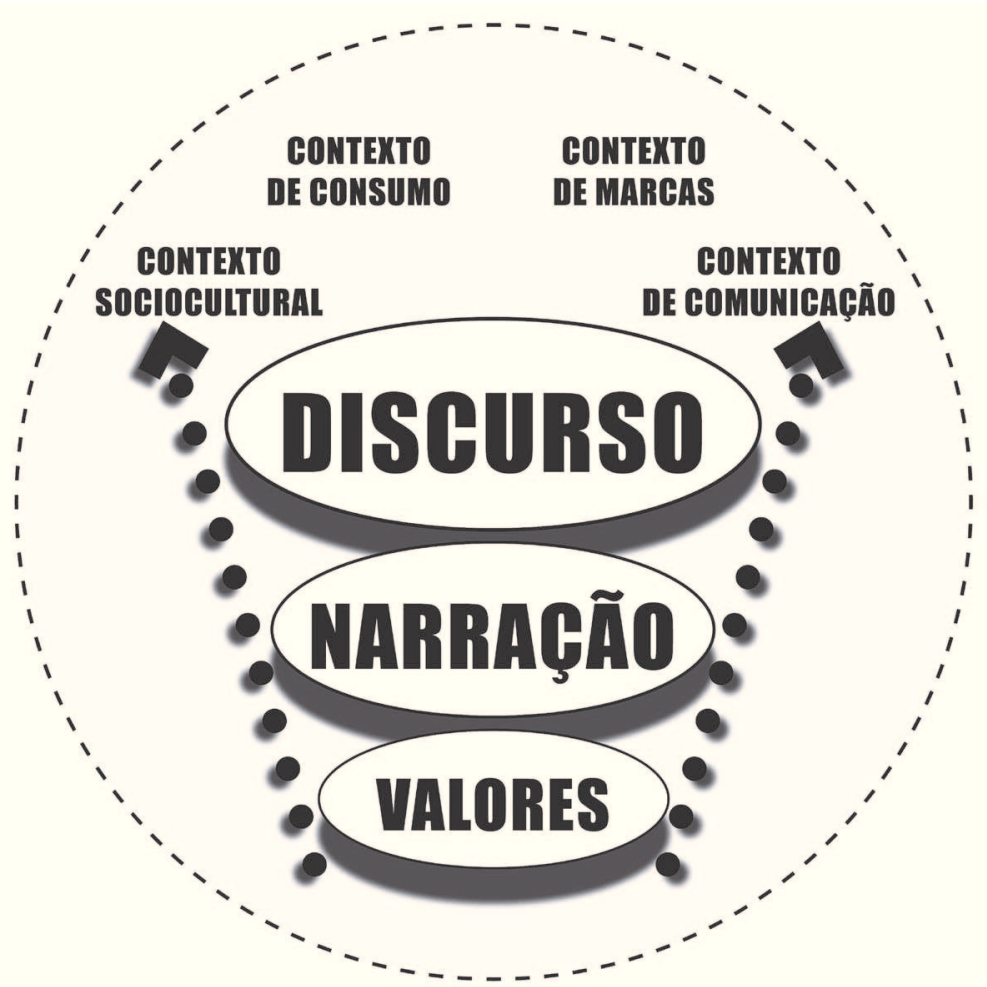

Fonte: SEMPRINI (2010)

\section{A PERCEPÇÃO DO DISCURSO DA MARCA}

O objetivo do presente artigo consiste em trabalhar o discurso publicitário como construtor de identidades, apoiando-se no percurso da manipulação e estabelecendo um contrato entre destinador (marca) e destinatário, a partir do qual toda a narrativa desenvolver-se-á como forma de manipulação. Para tanto, foi analisado o comercial L'Odyssée de Cartier (A Odisséia de Cartier), produzido em 2012 para comemorar os 165 anos da joalheria e dirigido por Bruno Aveillan. O valor pretendido pela marca está expresso em sua assinatura: Cartier. Joalheiros desde 1847.

Percebe-se que a intenção da Cartier é marcar a passagem do tempo com precisão, tradição, com luxo e sofisticação. $E$, ao serem invocados como endosso de sua marca, esses valores precisam ser comprovados e percebidos pelo público de maneira clara e convincente. A manipulação se apoia na tentação, na oferta de valores que este destinatário deseja, e na sedução, tentando convencer o outro. A maneira utilizada para compor esta percepção se expressa no comercial através da seguinte narrativa: o símbolo icônico da marca que os franceses chamam de pantera, mas na verdade é uma onça pintada brasileira, realiza uma viagem mundo afora rumo a momentos e locações vitais para a riquíssima história da Cartier.

A pantera viaja para uma coberta de neve São Petersburgo, lembrando as joias que a Cartier por décadas fabricou especialmente para a família do Czar da Rússia, para a China, onde enfrenta um dragão dourado, para a Índia, num palácio erguido sobre um elefante e repleto de joias, até saltar sobre as asas do 14-bis, de Alberto Santos-Dumont, quando se pode ver o clássico relógio Santos, encomendado em 1904 pelo brasileiro à Cartier. Foi Santos-Dumont quem popularizou o uso do relógio de pulso para homens em Paris, de onde a moda se estendeu. Do 14-bis a onça desce sobre o teto de um edifício até baixar até a Place Vendôme, principal sede da Cartier, de onde vai ao encontro da modelo Shalom Harlow dentro do Grand Palais. $O$ discurso visual agrega a essa narrativa a sofisticação, o brilho e o design, como podem ser percebidos nas cenas descritas na narrativa: 
Figura 6: A pantera
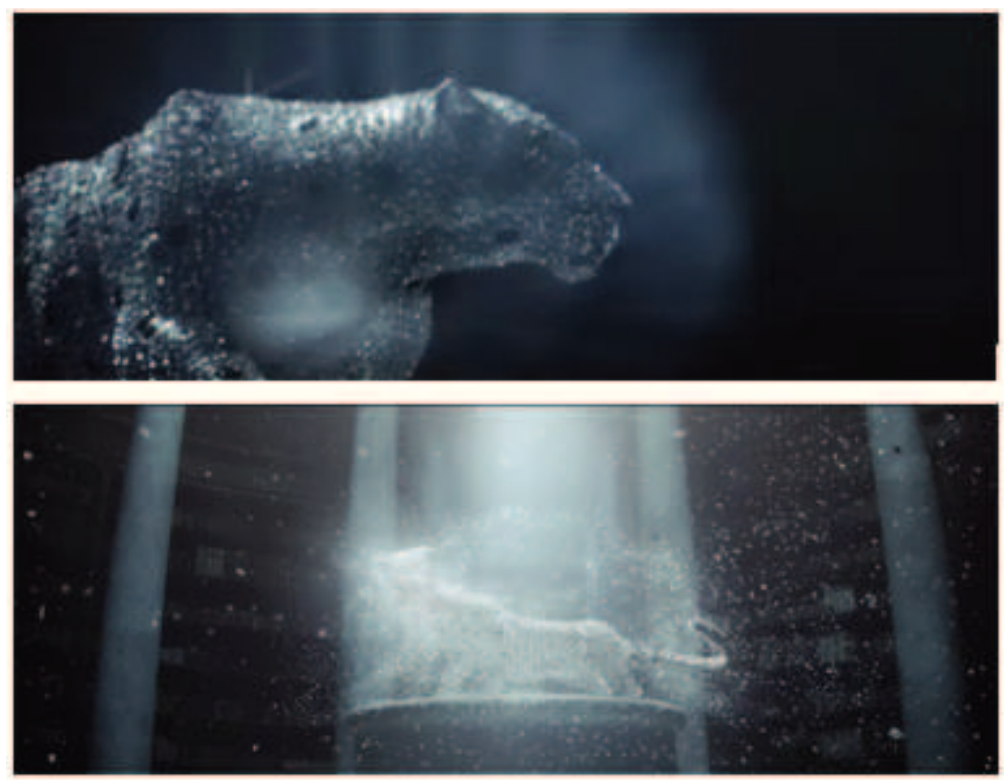

Fonte: print screen projeção via Youtube

A pantera, como símbolo icônico da marca primeiro representada por joias, surge imponente, por debaixo do brilho, demonstrando a presença da marca por trás de seus produtos.

\section{Figura 7: São Petersburgo}
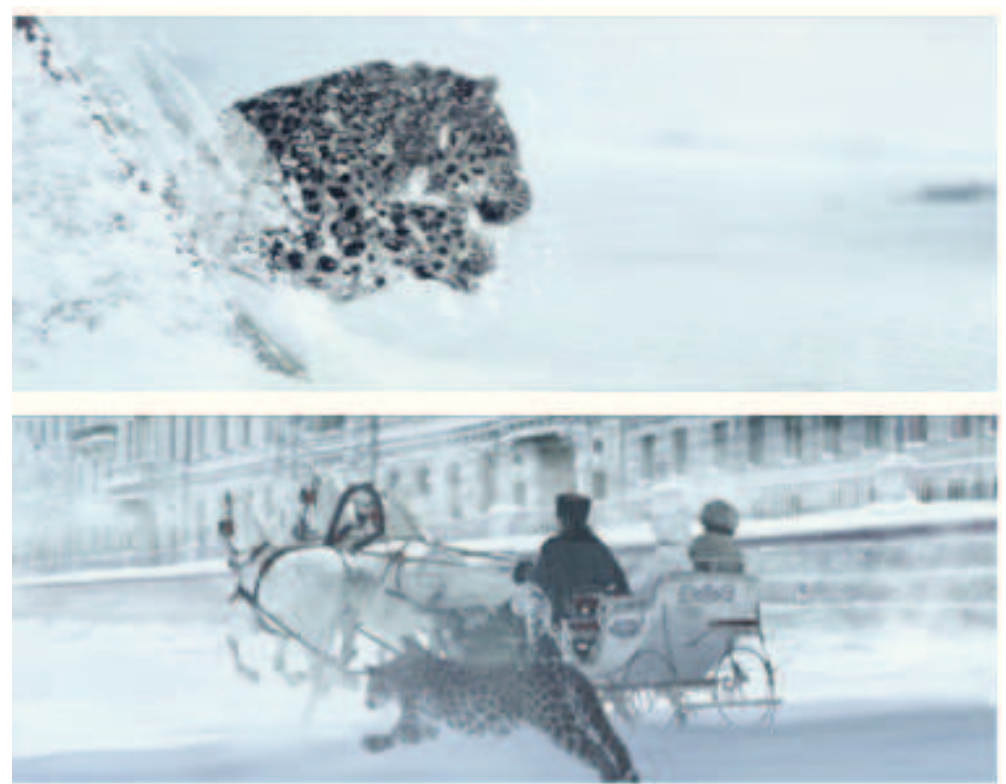

Fonte: print screen projeção via Youtube

A pantera chega à cidade de São Petersburgo, esta coberta de neve, acompanhando a família do czar da Rússia, em um sinal de familiaridade e associando nobreza à marca: são companheiros. 
Figura 8: China
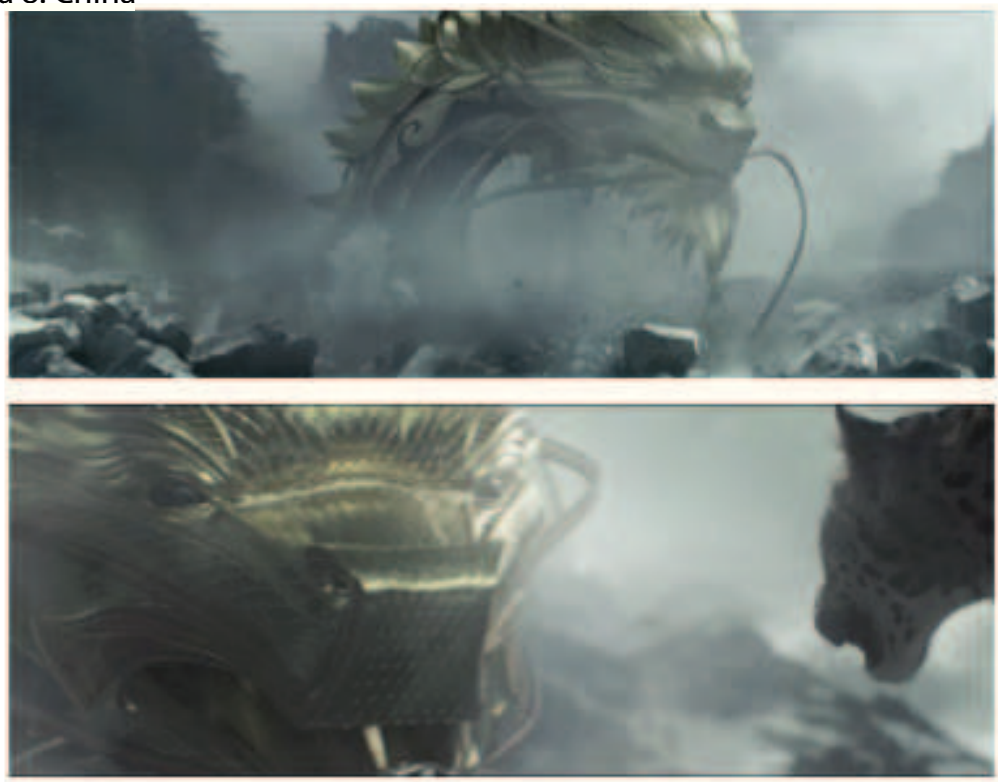

Fonte: print screen projeção via Youtube

$\mathrm{Na}$ China, enfrentando um dragão dourado, mais do que um passeio geográfico, fica a mensagem de que nem tudo que reluz é ouro, e o dragão é subjugado e transformado na Muralha da China. Isolacionismo ou isolamento? Seria uma identidade única?

Figura 9: India
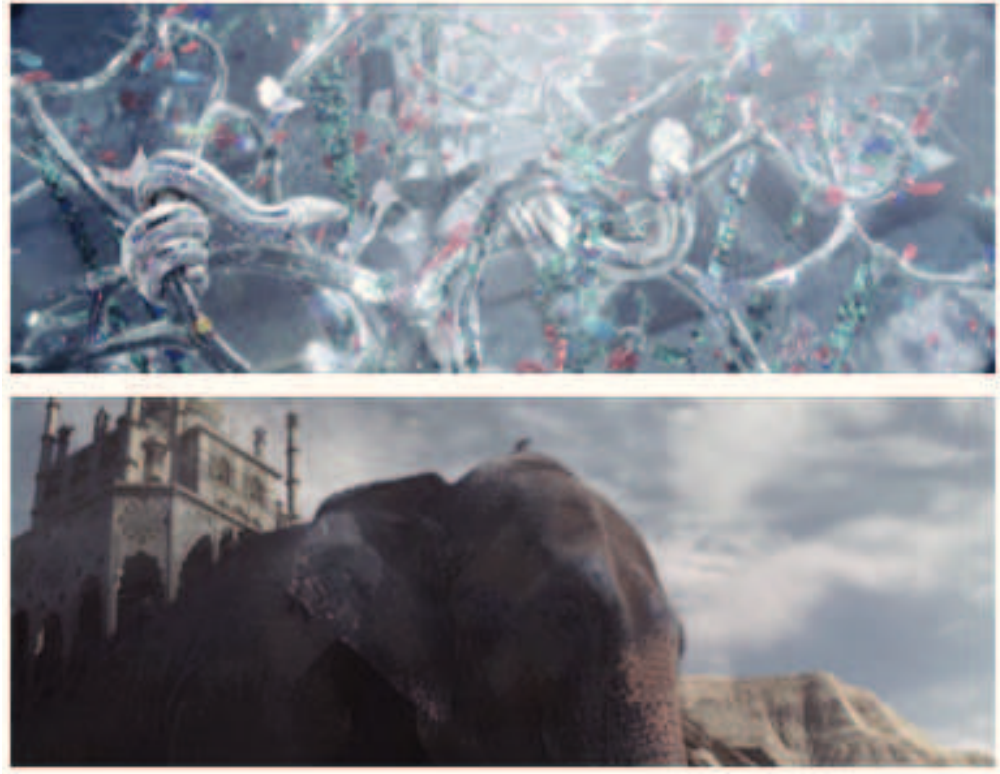

Fonte: print screen projeção via Youtube

Na Índia, a pantera caminha em um palácio repleto de joias, mostrando design e variedade, erguido sobre um elefante que caminha de maneira firme. Brincadeiras com a memória? Tradição? 
Figura 10: Santos Dumont
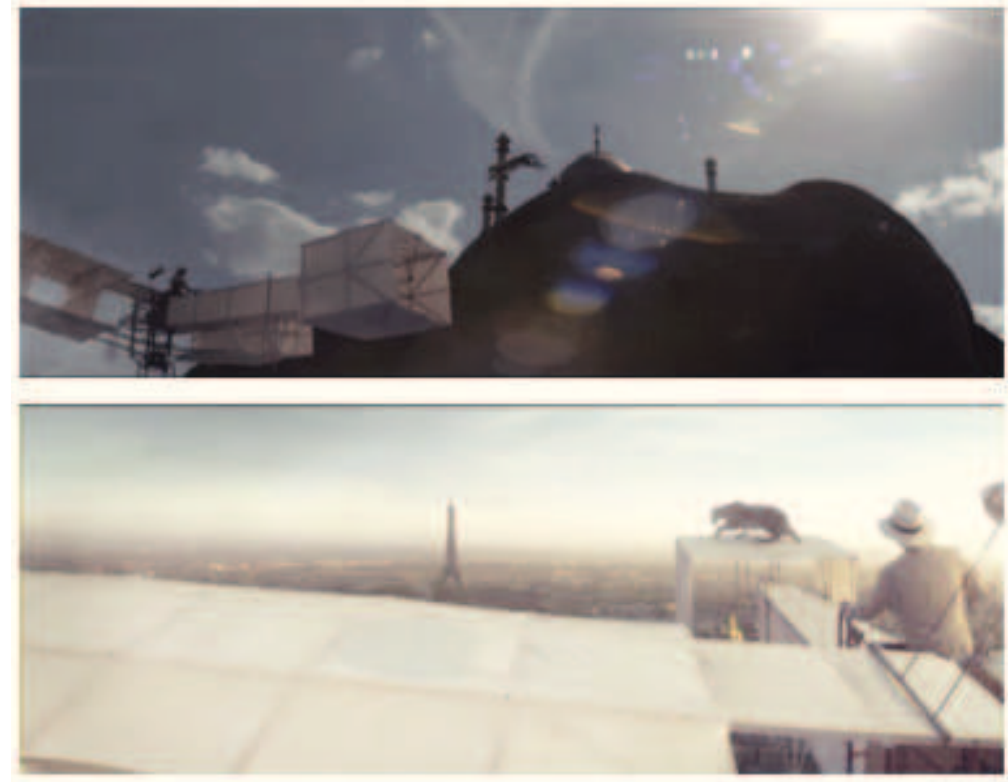

Fonte: print screen projeção via Youtube

Ao saltar sobre as asas do 14-bis, de Santos-Dumont, tradição, parceria e tecnologia se fundem, marcando o tempo e as conquistas.

Figura 11: Place Vendôme
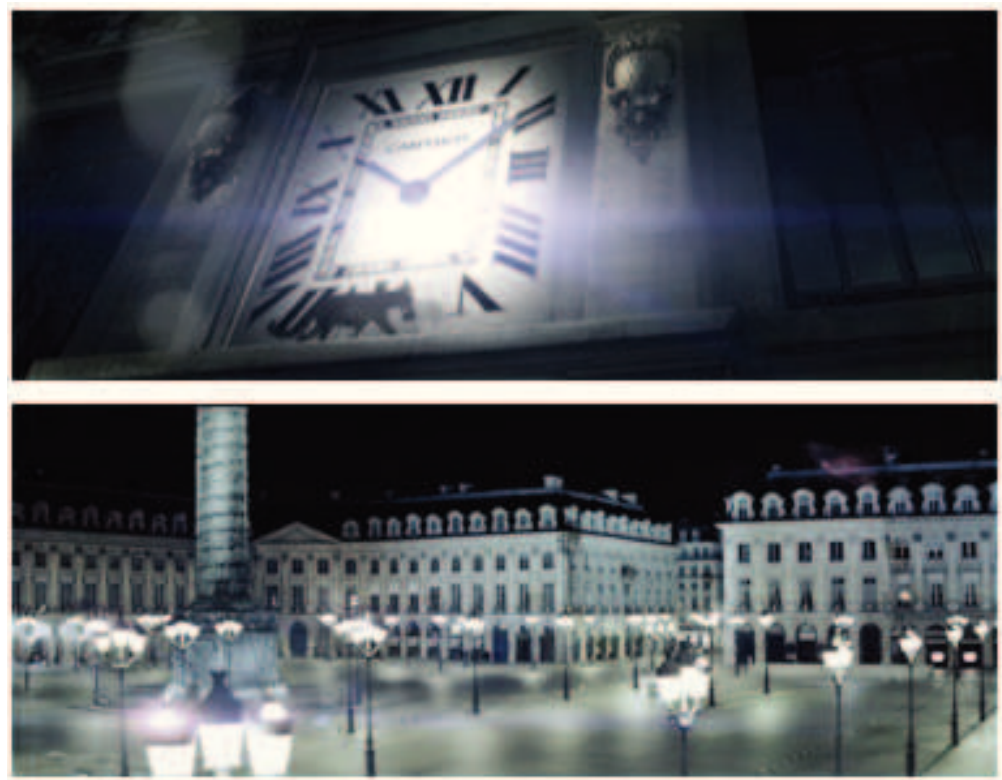

Fonte: print screen projeção via Youtube

Do 14-bis a pantera desce sobre o teto do edifício com um grande relógio Cartier, sinalizando o tempo, e caminha sobre a Place Vendôme, principal sede da joalheria Cartier. 
Figura 12: A modelo Shalom Harlow dentro do Grand Palais.
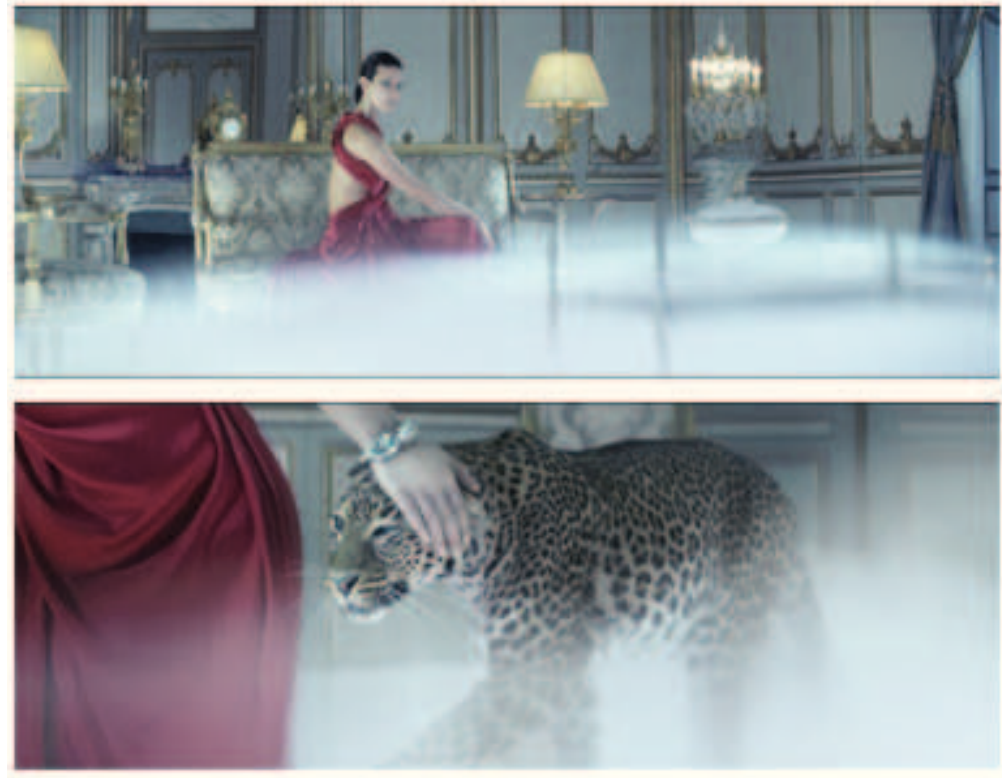

Fonte: print screen projeção via Youtube

O encontro com a modelo Shalom Harlow, dentro do Grand Palais, é a união de tradição, modernidade e beleza. Desperta o desejo do consumidor e seduz pelo brilho.

Figura 13: Assinatura final
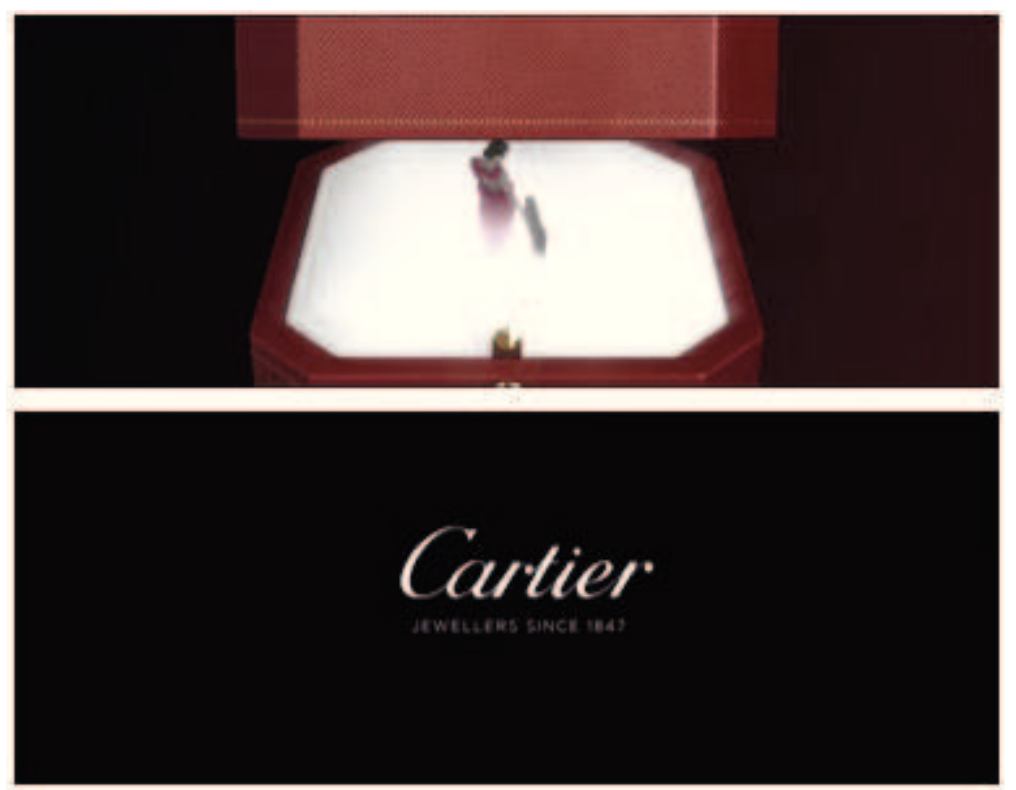

Fonte: print screen projeção via Youtube

E ao caminharem, literalmente, para a assinatura final, fica nítido o seguinte raciocínio: todo esse brilho e sofisticação se encontram nas embalagens das joias Cartier. Se você tiver a jia, você pertence a esse mundo. Tentação na oferta e sedução pela valorização.

Numa sociedade dominada pelo imaterial e pelo imaginário, o verdadeiro conteúdo de uma marca é seu enunciado pertinente aos consumidores. Os mundos possíveis que as marcas propõem ao indivíduo são construções de sentido organizadas, pertinentes e atraentes, sugere sistemas simbólicos que o 
auxiliam a pensar na marca. O discurso da marca Cartier nest vinheta comercial é construído através da narrativa, com ênfase na narrativa visual, na medida em que coerentemente os fatores brilho e beleza são aliados. Ambos característicos da marca Cartier, são apresentados de modo inovador no vídeo, seguindo a filosofia da joalheria; a qual, segundo seu site, consiste em "inovar sem perder a classe, transformar com bom gosto e ser a vanguarda da criação com a audácia da excelência", ser sinônimo de luxo (CARTIER, 2015).

\section{CONSIDERAÇÕES FINAIS}

As personalidades e as identidades se manifestam através do comportamento e de seus discursos, expressos e manipulados também por seu discurso publicitário. Quando uma marca comercial faz a opção de relacionar-se com seus consumidores, um processo de comunicação precisa estabelecer-se e, ao se fazer isso, surge o caráter simbólico da interação da composição dos valores expressos pelas marcas, impondo a necessidade da análise sobre o que é essa comunicação, como ela se relaciona com o mercado e qual é a importância e a função de sua aparência na comunicação, construindo sua identidade.

A marca ganha sua identidade e uma dimensão quando ela se manifesta impactando diretamente nos projetos da marca através das percepções do público alvo e seus diferentes comportamentos com atitudes, modos de agir e reagir que são influenciados, entre outros fatores, pelas experiências de vida e experiências com a marca.

Uma das grandes estratégias das marcas comerciais é a busca de um diferencial para atingir e manter os seus consumidores, buscando criar um reconhecimento e uma identificação. A marca quer ser percebida e quer fazer isso através de seu discurso. A comunicação de marketing, que até então acreditava na eficiência da segmentação por grupos - etários, sociais, econômicos - hoje corre atrás dos aspectos individuais do consumidor. Para as empresas e o marketing se estabelece um processo de aprendizagem fruto da relação de oferta e demanda, uma adaptação dinâmica fazendo com que os mercados se tornem mais performativos. Na medida em que se é solicitado, as experiências são capitalizadas, o consumidor adquire o domínio das técnicas, das linguagens, dos processos comunicacionais, das estratégias de exibição, circulação e distribuição do mercado, exercitando e exercendo sua capacidade de narrativa. Assim, pode-se também considerar que a sociedade se movimenta através das marcas.

O processo é rico para uma comunicação plena e, em nosso caso especifico, para perceber uma marca na sociedade: a identificação visual e seus elementos ajudam a formar a marca e a percepção de seu conceito. Porém, esses elementos técnicos e funcionais não são o suficiente para justificar o comportamento dos consumidores, por mais que eles expliquem a leitura mas não deixam clara a possibilidade das múltiplas interpretações que uma marca pode ter.

A percepção dos elementos, ainda que a princípio ocorra de forma individual, tem na sua soma, no conjunto de expressões, a corroboração na formação da imagem (como se é visto) mental a respeito de quem se trata (organização, produto ou serviço). Como é cada vez mais natural o uso de diferentes mídias para a veiculação de informação referente a um mesmo produto, é importante que se consiga estabelecer relações e ligações entre estas diferentes mídias. Se formos analisar estes produtos, sejam separadamente ou colocando conjuntamente, perceberemos que deverá existir uma constância no que diz respeito ao uso de cores, formas, tipologia, imagens, texturas, além de narrativas e histórias coerentes com os valores da marca, mesmo em diferentes mídias. Isso, pois fortalecem e criam uma identidade da marca como um todo na mente do consumidor. Assim, estudos teóricos, como o da semiótica, são grandes contribuições para esse entendimento do que é o discurso da marca e sua importância na construção da identidade.

Baseado na decupagem do comercial, conclui-se que a comunicação da marca 
Cartier se expressou através da comunicação formal, ou seja, através do texto publicitário e do testemunho dos atores envolvidos constituindo o que se pode chamar de propaganda comercial de marca. Foi feita uma mediação entre a marca e o consumidor num processo de respostas com significados embutidos. Isso significa que a marca adquiriu relevância através da publicidade - e o consumidor pode ser envolvido por ela - através de um discurso que construiu uma narrativa simbólica.

A identidade de uma marca, neste comercial, foi o resultado do processo de manipulação, de simbolização e da construção da autoimagem de uma entidade através do discurso, notadamente o visual. Assim, o caráter simbólico surgiu do fato das simbolizações interagirem na composição dos valores expressos sobre a marca, construindo sua identidade. Considera-se que é possível a aplicação da comunicação publicitária na divulgação do discurso da marca. As personalidades e as identidades se manifestam através do comportamento e de seus discursos.O processo de construção da marca e suas manifestações são resultantes de programas e ações de comunicação que, ao atuarem como manifestações da marca, interferem e constroem, ao mesmo tempo, a identidade e a imagem. E a publicidade se mostrou como sendo uma das ações de comunicação mais tradicionais.Por fim, considera-se que os assuntos publicidade, semiótica e discurso da marca são densos e complexos, sendo claramente possível propor e realizar outras associações, aproximações e amarras tanto teóricas como teóricoaplicadas. Todavia, este trabalho limitou-se à intenção de iniciar a discussão sobre os assuntos, indicando a contribuição que a comunicação para ele pode dispor.

\section{NOTAS}

[1] https://www.youtube.com/watch?t=51\&v=yaBNjTtCxd4

\section{REFERÊNCIAS}

BATEY, Mark. $\mathbf{O}$ significado das marcas: como as marcas ganham vida na mente dos consumidores. Rio de Janeiro: Best Business, 2010.

CARTIER. A Maison Cartier - O renomado joalheiro e relojoeiro francês, noivas e artigos em couro de luxo. Disponível em: <http://www.cartier.com.br/maison>. Acesso em 04 de out. 2015.

FLOCH, Jean-Marie. Semiótica, marketing y comunicación. Bajo los signos, las estrategias, Barcelona, Paidós, [Sémiotique, marketing et communication. Sous les signes, les stratégies, Paris, Presses Universitaires de France, 1991],1993.

GREIMAS, Algirdas J.; COURTÉS, Joseph. Dicionário de Semiótica. São Paulo: Contexto, 2008.

SEMPRINI, Andrea. A marca pós-moderna: poder e fragilidade da marca na sociedade contemporânea. São Paulo: Estação das Letras e Cores, 2010.

VILLAS-BOAS, André. Identidade e Cultura. Rio de Janeiro: 2AB, 2002.

\section{Alvaro Roberto Dias}

É doutor na área de Midias do Conhecimento do Programa de Pós-Graduação em Engenharia e Gestão do Conhecimento EGC/UFSC (2014), mestrado em Ciências da Linguagem pela Universidade do Sul de Santa Catarina (2006) e graduação em Comunicação Social pela Fundação Armando Álvares Penteado (1978).

É professor titular da Univali - Universidade do Vale do Itajaí, com experiência na área de Comunicação, com ênfase em Publicidade e Propaganda, Design Gráfico e Representação Visual, atuando principalmente nos seguintes temas: publicidade, comunicação visual, semiótica e branding. 
É integrante dos grupos de pesquisa Comunicação, Cultura e Conhecimento, da UNIVALI, e do grupo SIGMO - Significação da marca, informação e comunicação organizacional, da UFSC.

Principais publicações:

CULTURA, LINGUAGEM GRÁFICA E ALFABETISMO VISUAL. Educação Gráfica, 2013.

Identidade de marca e simbologia na interface digital. Estudos em Design (Online), 2012.

A INFORMAÇÃO GRÁFICA COMO CONSTRUTORA DE IDENTIDADE VISUAL DE MARCA E SUA COMUNICAÇÃO NOS MEIOS IMPRESSOS E DIGITAIS. Cultura Visual, 2012.

Identidade, Marca e Consumo: Construções Simbólicas na Tessitura da Cultura. DAPesquisa, 2012.

Emotion, Advertising and Branding: the Identity of Brands Built by Advertising Discourse. In: Senses \& Sensibility, 2013, Florianópólis. Senses \& Sensibility in Florianópolis: Advertising, Design, Fashion, Marketing, Photography and Visual Culture in the Right Place. Lisboa: UNIDCOM/IADE, 2013.

AS VÁRIAS LEITURAS DE UMA IDENTIDADE VISUAL.. In: VI SEMINÁRIO LEITURA DE IMAGENS PARA A EDUCAÇÃO: MÚLTIPLAS MÍDIAS, 2013, Florianópolis. VI SEMINÁRIO LEITURA DE IMAGENS PARA A EDUCAÇÃO: MÚLTIPLAS MÍDIAS. Florianópolis: Ceart, 2013. v. 6. p. 45-56. 